\title{
HEPATITE AGUDA COLESTÁTICA PELO PROPILTIOURACIL. Relato de caso
}

\author{
Mônica Beatriz PAROLIN*, Reginaldo Werneck LOPES**, \\ José Ederaldo Queiroz TELLES***, Sergio Ossamu IOSHII*** e Nemer HAJAR****
}

\begin{abstract}
RESUMO - Propiltiouracil é uma droga amplamente utilizada no tratamento do hipertiroidismo. A hepatotoxicidade é um dos efeitos colaterais mais raros e também mais graves associados a ela. Relata-se um caso de hepatite aguda colestática que acomete um jovem de 15 anos em uso de propiltiouracil para tratamento de hipertiroidismo. Causas virais, metabólicas e autoimunes foram excluidas e a biopsia hepática revelou achados histopatológicos sugestivos de hepatite colestática induzida por droga. Com a suspensão da droga, houve remissão dos sintomas e normalização progressiva das provas de função hepática. Raramente, os pacientes em uso de propiltiouracil podem desenvolver injúria hepática grave.
\end{abstract}

DESCRITORES - Propiltiouracil. Hipertiroidismo. Hepatite, induzida por droga.

\section{INTRODUÇÃO}

O propiltiouracil (PTU), droga pertencente ao grupo químico das tiouréias, vem sendo usado largamente no tratamento do hipertiroidismo, desde sua apresentação em $1946^{(2)}$. No ano seguinte a seu advento surgiu o primeiro relato de complicações de seu uso, entre as quais, a agranulocitose e a icterícia hepatocelular ${ }^{(14)}$.
Até 1996 foram publicados cerca de 30 casos em que o efeito do PTU sobre o fígado se fez presente, alguns com desenlace fatal ${ }^{(4,5,7,9,13,18)}$. De maneira geral, as complicações relatadas, como erupção cutânea, urticária, febre, dores articulares, leucopenia, artrite e alterações das provas de função hepática desaparecem pela interrupção da droga $a^{(10,11)}$. Entretanto, casos mais graves de colestase intensa ou necrose submaciça ${ }^{(11,20)}$ devem servir de

Serviço de Transplante Hepático e Serviço de Anatomia Patológica - Hospital de Clínicas da Universidade Federal do Paraná - HC-UFPR.

* $\quad$ Médica Hepatologista do Serviço de Transplante Hepático do HC-UFPR.

** $\quad$ Professor Sênior do Departamento de Clínica Médica do HC-UFPR.

*** Professor do Serviço de Anatomia Patológica do HC-UFPR.

**** Médico do Serviço de Cirurgia do Aparelho Digestivo do HC-UFPR.

Endereço para correspondência: Dra. Mônica Beatriz Parolin - Rua Lamenha Lins, 2280 - 80220-080 - Curitiba, PR. 
advertência para os endocrinologistas, no sentido da prevenção de tais complicações, através da solicitação de provas de função hepática nas primeiras semanas do tratamento e de alerta aos pacientes para o possível aparecimento de icterícia, colúria, erupção cutânea, fadiga e fraqueza.

\section{RELATO DE CASO}

STM, masculino, branco, com 15 anos de idade, portador de hipertiroidismo há 3 anos, fazia uso regular de PTU, na dose de 100 $\mathrm{mg} /$ dia, há 15 meses. Sete dias antes da primeira consulta, apresentou astenia, mialgias, colúria e fezes descoradas, coincidindo com o aparecimento de icterícia. Negava uso de outras drogas, exceto ácido acetil-salicílico, recentemente, pelos sintomas de mialgias e astenia. Tampouco apresentava história de consumo de álcool, exposição a sangue ou derivados ou situações de risco para hepatites. Ao exame físico, denotava bom estado geral e icterícia intensa de pele e escleróticas, tiróide palpável, hepatomegalia e esplenomegalia discretas, na ausência de outros estigmas de hepatopatia crônica. Pelos resultados dos exames laboratoriais iniciais (ALT $1070 \mathrm{UI} / \mathrm{L}$, AST $1060 \mathrm{UI} / \mathrm{L}$, bilirrubinas totais $25,1 \mathrm{mg} / \mathrm{dL}$, bilirrubina direta $14,9 \mathrm{mg} / \mathrm{dL}$ ) suspeitou-se de hepatite aguda viral, mas, subseqüentemente, os marcadores sorológicos para hepatite A (anti-VHA IgM), hepatite B (anti-HBc IgM, AgHBs) e hepatite C (anti-VHC) mostraram-se negativos, invalidando, assim, aquela hipótese diagnóstica. As dosagens de ceruloplasmina de $33 \mathrm{mg} / \mathrm{dL}$ e alfa-1antitripsina de $311 \mathrm{mg} / \mathrm{dL}$ afastaram, também, as possibilidades de hepatopatia por doença de Wilson ou por deficiência de alfa-1antitripsina. Os testes sorológicos para citomegalovírus e EpsteinBarr foram igualmente negativos.

Face à conhecida potencialidade hepatotóxica do PTU, decidiuse pela suspensão da droga, iniciando-se, em substituição, propranolol (40 mg/dia) para controle das manifestações clínicas do hipertiroidismo. A ultra-sonografia abdominal revelou apenas esplenomegalia discreta. Apesar do bom estado geral do paciente, agravaram-se as provas de função hepática, instalando-se importante quadro de colestase (bilirrubinas totais $39 \mathrm{mg} / \mathrm{dL}$, bilirrubina direta $31 \mathrm{mg} / \mathrm{dL}$, fosfatase alcalina $1319 \mathrm{UI} / \mathrm{L}$ ). Exames destinados a descartar hepatite autoimune revelaram apenas positividade para $o$ FAN, no valor de 1:160 (padrão granular nuclear). No $10^{\circ}$ dia de internamento, a bilirrubina sérica total atingiu $46,7 \mathrm{mg} / \mathrm{dL}$, persistindo elevados os valores das aminotransferases (AST $562 \mathrm{UI} / \mathrm{L}$, ALT $678 \mathrm{UI} / \mathrm{L}$ ) e redução na atividade da protrombina (50\%). Face ao valor elevado do FAN e pela ausência de contra-indicação, na possibilidade de tratar-se de hepatite autoimune, optou-se pelo início de corticoterapia (prednisona $60 \mathrm{mg} / \mathrm{dia}$ ). A partir de então, constatou-se progressiva melhora dos exames, tendo sido possível realizar, uma semana depois, biopsia hepática por agulha que revelou discreta alteração da arquitetura lobular caracterizada por alargamento portal às custas de infiltrado inflamatório mononuclear, raros eosinófilos e fibrose discreta. Discreta proliferação de ductos biliares foi observada. Os achados lobulares consistiram na balonização dos hepatócitos, que apresentavam, com freqüência, pigmento acastanhado de bilirrubina, além de focos de infiltrado inflamatório mononuclear e congestão das veias centro-lobulares com discreto edema sub-endotelial (Fig. 1). Imediatamente promoveu-se a redução progressiva da prednisona ( $5 \mathrm{mg}$ por semana), na convicção de tratarse de hepatite colestática determinada pelo propiltiouracil. Controle clínico e laboratorial, dois meses e meio após o início do quadro, revelou completa normalização das provas de função hepática (bilirrubinas totais $0,55 \mathrm{mg} / \mathrm{dL}$, AST $11 \mathrm{UI} / \mathrm{L}$, ALT $44 \mathrm{UI} / \mathrm{L}$, FA 82 $\mathrm{U} / \mathrm{L}$, gamaglutamiltranspeptidase $24 \mathrm{U} / \mathrm{L}$, TAP 100\%). A última avaliação, realizada quatro meses após o episódio da hepatite colestática, mostrou persistência de provas de função hepática normais, porém hipertiroidismo descompensado, para o qual indicouse tratamento com iodo radioativo.

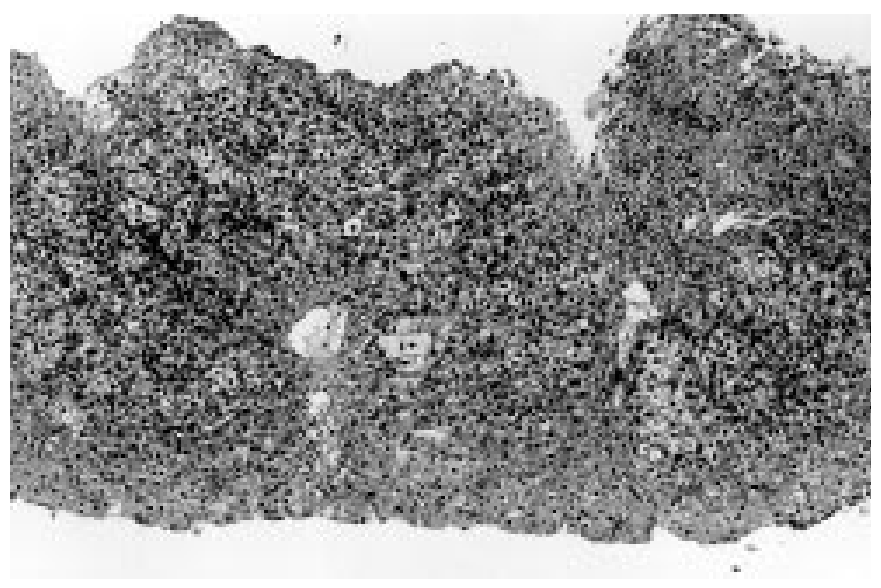

FIGURA 1 - Fotomicrografia de biopsia hepática por agulha demonstra balonização dos hepatócitos, discreto alargamento portal por células inflamatórias (H \& E 100x).

\section{DISCUSSÃO}

Fato reconhecido, o hormônio tiroidiano exerce ação direta sobre o hepatócito, regulando, em concentrações fisiológicas, grande número de funções metabólicas fundamentais. No hipertiroidismo as alterações hepáticas descritas variam desde a verificação de anormalidades bioquímicas leves, até lesões histológicas inespecíficas devidas à isquemia severa centrolobular ${ }^{(3,6)}$. Quando ao hipertiroidismo se associa à insuficiência cardíaca, esta e a hipoxemia representam importantes fatores para a disfunção hepática ${ }^{(11)}$. Tais fatos devem ser judiciosamente considerados quando se pretende relacionar o aparecimento de sintomas e sinais de hepatopatia ao uso do 
propiltiouracil durante o tratamento do hipertiroidismo. Entretanto, basicamente, as alterações hepáticas decorrentes do hipertiroidismo desaparecem quando se mantém o paciente eutiroidiano e as devidas ao PTU regridem pela retirada da droga. Além disso, mesmo em casos de hipertiroidismo grave, as bilirrubinas e as aminotransferases apresentam-se apenas levemente alteradas ${ }^{(11,17)}$.

A hepatotoxicidade devida ao PTU representa diagnóstico de exclusão, como sucede com outras drogas, havendo relação temporal entre o emprego da droga e o aparecimento das alterações clínicas e bioquímicas. Nestas condições, a fisiopatologia da afecção hepática é controversa. Para uns, a observação de normalização das aminotransferases pela redução da dose de PTU sugere que o efeito tóxico é dose-dependente ${ }^{(12)}$, contrariando assertiva de outros, que sugerem tratar-se de reação imunitária desencadeada por linfócitos sensibilizados pelo $\mathrm{PTU}^{(8,9,16,19)}$. Durante o tratamento pelo PTU a participação do sistema imunitário pode ser constatada pela presença de anticorpos antinucleares (ANA) e antitiroidianos, reação autoimune que desaparece pela suspensão da droga. A positividade do ANA em pacientes sob tratamento com PTU é considerada como parte da reação "lupus-simile", ocasionalmente observada no curso desse tratamento $^{(1,9)}$.

No presente caso, embora a presunção diagnóstica inicial tenha se inclinado para hepatite autoimune, a conduta adotada foi consoante a de outros autores que recomendam a suspensão imediata do PTU na presença de manifestações hepáticas, mesmo que anticorpos antinucleares estejam presentes ${ }^{(9)}$. A confusão com hepatite autoimune devida à valorização inicial da positividade do ANA (1:160) é referida por outros autores ${ }^{(15)}$, mas sua informação obedeceu à negatividade dos outros marcadores de autoimunidade e ao critério histológico, sugestivo de lesão por droga (Fig. 1).

A intensidade das alterações observadas nas provas hepáticas com valores de aminotransferases acima de $1000 \mathrm{UI} / \mathrm{L}$ e de níveis de bilirrubinas totais que ascenderam a mais de $40 \mathrm{mg} / \mathrm{dL}$, permite excluir o hipertiroidismo como causa de hepatopatia. O diagnóstico de hepatopatia colestática pela ação tóxica do PTU se reforça pela semelhança desse caso a outros da literatura, assim como pela imediata melhora do paciente após retirada da droga e a manutenção, até o presente, de normalidade das provas hepáticas. Entretanto, os níveis de TSH da última revisão (junho/98) indicam a persistência do hipertiroidismo, o que recomenda o encaminhamento do paciente aos cuidados especializados de um endocrinologista.

Esta observação clínica, à semelhança das já descritas na literatura médica, alerta para o risco de pacientes sob uso do propiltiouracil desenvolverem lesões hepatocelulares graves. Assim, a droga deverá ser prontamente descontinuada quando se instale icterícia ou elevação das aminotransferases, enquanto a investigação diagnóstica é conduzida.

Parolin MB, Lopes RW, Telles JEQ, Ioshii SO, Hajar N. Acute cholestatic hepatitis induced by propylthiouracil. Case report. Arq Gastroenterol 2000;37(2):129-132.

ABSTRACT - Propylthiouracil is widely used to treat patients with hyperthyroidism. However, propylthiouracil-induced hepatitis is an uncommon entity. The case of a 15-year-old boy treated with propylthiouracil for hyperthyroidism who developed a cholestatic acute hepatitis is reported. Viral, metabolic and autoimmune liver diseases were excluded and liver biopsy showed a pattern suggestive of druginduced cholestatic hepatitis. After discontinuating the drug, there was a progressive resolution of symptoms and normalization of liver biochemical tests. Despite its rarity, patients receiving propylthiouracil are exposed to develop severe hepatotoxicity.

HEADINGS - Propylthiouracil. Hyperthyroidism. Hepatitis, drug induced. 


\section{REFERÊNCIAS BIBLIOGRÁFICAS}

1. Armheim JA, Kennt FM, Ross D. Granulocytopenia, lupus-like syndrome, and other complications of propylthiouracil therapy. Pediatrics 1970;76:54-63.

2. Astwood EB, Vanderlaan WP. Treatment of hyperthyroidism with propylthiouracil. Ann Intern Med 1946;25:813-21.

3. Bayraktar M, Van Thiel DH. Abnormalities in measures of liver function and injury in thyroid disorders. Hepatogastroenterology 1997;44:1614-8.

4. Colwell AR Jr, Sando DE, Lang SJ. Propylthiouracil induced agranulocytosis, toxic hepatitis, and death. JAMA 1952;148:639-41.

5. Eisen MJ. Fulminant hepatitis during treatment with propylthiouracil. N Engl J Med 1953;249:814-6.

6. Fong TL, McHutchison JG, Reynolds TB. Hyperthyroidism and hepatic disfunction. A case series analysis. J Clin Gastroenterol 1992;14:240-4.

7. Hanson HS. Propylthiouracil and hepatitis. Two cases and a review of the literature. Arch Intern Med 1984;144:994-6.

8. Hardee JT, Barnett AL, Thannoun A, Eghtesad B, Wheller D, Jamal MM Propylthiouracil-induced hepatotoxicity. West J Med 1996;165:144-7.

9. Jonas MM, Eidson MS. Propylthiouracil hepatotoxicity: two pediatric cases and review of the literature. J Pediatr Gastroenterol Nutr 1988;7:776-9.

10. Khovidhunkit W, Farese RV Jr. Resolution of propylthiouracil-induced hepatic failure after treatment of thyrotoxicosis. West J Med 1997;66:353-6.

11. Levy M. Propylthiouracil hepatotoxicity. A review and case presentation. Clin Pediatr 1993;32:25-9.
12. Liaw YF, Huang MJ, Fan KD, Li KL, Wu SS, Chen TJ. Hepatic injury during propylthiouracil therapy in patients with hyperthiroidism - a cohort study. Ann Intern Med 1993;118:424-8.

13. Limaye A, Ruffolo R. Propylthiouracil-induced fatal hepatic necrosis. Am J Gastroenterol 1987;82:152-4.

14. Livingston HJ, Livingston SF. Agranulocytosis and hepatocelular jaundice. JAMA 1947;135:422-5.

15. Maggiore G, Larizza D, Lorini R, Scotta MS, Severi F. Propylthiouracil hepatotoxicity mimicking autoimmune chronic active hepatitis in a girl. J Pediatr Gastroenterol Nutr 1989;8:547-8.

16. Mihas AA, Holey P, Koff RS, Hirschowitz BI. Fulminant hepatitis and lymphocyte sensitization due to propylthiouracil. Gastroenterology 1976;70:770-4.

17. Movit ER, Gerstl B, Davis AE. Needle liver biopsy in thyrotoxicosis. Arch Intern Med 1953;91:729-39.

18. Safani MM, Tatro DS, Rudd P. Fatal propylthiouracil-induced hepatitis. Arch Intern Med 1982;142:838-9.

19. Sarkany I. Lymphocyte transformation in drug hypersensitivity. Lancet 1967;1:743-5.

20. Westphal AS. Hepatotoxicity from propylthiouracil. Southern Med J 1994;87:943-7. 